\title{
Nutrient- and non-nutrient-based natural health product (NHP) use in adults with mood disorders: prevalence, characteristics and potential for exposure to adverse events
}

\author{
Karen M Davison ${ }^{1,2^{*}}$ and Bonnie J Kaplan ${ }^{1,3}$
}

\begin{abstract}
Background: To address knowledge gaps regarding natural health product (NHP) usage in mental health populations, we examined their use in adults with mood disorders, and explored the potential for adverse events.

Methods: Food and NHP intake was obtained from 97 adults with mood disorders. NHP data was used to compare prevalence with population norms (British Columbia Nutrition Survey; BCNS). Bivariate and regression analyses examined factors associated with NHP use. Assessment of potential adverse effects of NHP use was based on comparing nutrient intakes from food plus supplements with the Dietary Reference Intakes and by reviewing databases for reported adverse health effects.

Results: Two-thirds (66\%; $95 \%$ Cl 56 to 75$)$ were taking at least one NHP; $58 \%(95 \% \mathrm{Cl} 47$ to 68$)$ were taking NHPs in combination with psychiatric medications. The proportion of each type of NHP used was generally higher than the BCNS (range of p's $<0.05$ to 0.0001 ). When intakes from food and NHP sources were combined, a small proportion exceeded any Lowest-Observed-Adverse-Effect-Levels: only for niacin $(n=17)$ and magnesium $(n=6)$, two nutrients for which the potential for adverse effects is minimal. Conversely, about $38 \%$ ( $95 \% \mathrm{Cl} 28$ to 49 ) of the sample were taking a non-nutrient based NHP for which previous adverse events had been documented.

Conclusions: The prevalent use of NHPs in this population suggests that health care providers need to be knowledgeable about their characteristics. The efficacy and safety of NHPs in relation to mental health warrants further investigation.
\end{abstract}

Keywords: Natural health products, Adverse events, Mood disorders

\section{Background}

People with mental health conditions often use a variety of therapeutic alternatives which are not necessarily disclosed to their primary health care provider. Remedies used may include natural health products (NHPs), defined as agents that include constituents such as vitamins and minerals, herbs, homeopathic medicines, traditional medicines, probiotics, and other products like amino acids and essential fatty acids [1].

\footnotetext{
* Correspondence: karen.davison@ubc.ca

'Department of Community Health Sciences, University of Calgary, Calgary, $\mathrm{AB}$, Canada

${ }^{2}$ University of British Columbia, School of Population and Public Health, 2206 East Mall, Vancouver BC V6T 1Z3, Canada

Full list of author information is available at the end of the article
}

National surveys of general populations have found that NHP use is increasing around the world [2-5], but few studies have examined individuals with mental health conditions. Available data suggest that NHP use tends to be higher in those with anxiety and depressive disorders [6-11]. From a public health perspective, there is some concern that NHPs may interact with conventional therapies. For example, studies have reported that St. John's wort combined with trazodone, sertraline, or nefazodone may cause serotonin syndrome [12]. Reporting the potential for adverse health-related events such as these has gained increased attention globally as the information serves as a means to prevent harm to individuals and help formulate recommendations for health systems 
change [13]. Conversely, other investigations report beneficial effects of NHPs including lowered requirement doses of medications [14-17]. In either case, it would be useful to know more about NHP use in people with mental health conditions. This analysis examined characteristics of NHP use including potential for adverse events in adults with mood disorders.

\section{Methods}

\section{Subjects, settings and procedures}

Data from a cross-sectional nutrition survey of adults ( $>18$ years; $n=97$ ) that were randomly selected from the Mood Disorders Association of British Columbia (MDABC) membership list and resided in the lower mainland of British Columbia $(n=1400)$ was used; the list was provided to researchers by the MDABC. Sample size verification was obtained using one-sample inference for a binomial proportion [18] with estimates of NHP use at $60 \%$ in the study population and general population use being 46\% [19], alpha of 0.05 , and statistical power of $80 \%$.

Individuals $(\mathrm{n}=146)$ randomly selected from the MDABC membership list were first sent a letter inviting their participation in the study. Subsequent to the invitation letter, a research staff member phoned the potential participant to ask if the research coordinator could contact them to discuss the project. Ten attempts were made to contact the potential participant if there continued to be no answer. Then the file was closed. For those who agreed to participate, the research coordinator reviewed procedures of the study over the phone including instructions of how to complete their food records that were mailed out to them. Overall, 97\% of the 146 names drawn for the study were resolved; that is, they were located and contacted to participate. Of those, a range of 124 to 129 individuals were considered in-scope or eligible based on information available. Individuals were considered out-of-scope or not eligible if they were dead, had moved out of the area, or exhibited at least one of the exclusion criteria (e.g., pregnant, lactating, living in an institution). Of those contacted and eligible, 3\% refused to participate in the study and $2 \%$ did not show up for their appointment (based on the upper bound of 129 eligible).

The study protocol including details about verification of mood disorder diagnosis (i.e., bipolar I, bipolar II, and depressive disorder) using the Structured Clinical Interview for DSM-IV Axis I Disorders [20] and Global Assessment of Functioning (GAF) [21], exclusion criteria (i.e., presence of another condition impacting mental health), current symptoms of depression and mania based on the Hamilton Depression Scale (Ham-D) [22], and Young Mania Rating Scale (YMRS) [23], and collection of nutrient intake data are detailed elsewhere [24]. Of those that participated in the screening to assess eligibility, two were found to be ineligible. The study's protocol including consent procedures were approved by the University of Calgary's Conjoint Health Research Ethics Board. The consent procedures involved first mailing the study's consent forms to those who agreed to participate, so that they could review it at their leisure. Then when the participants attended their appointment, they first reviewed the consent forms with the research coordinator or clinical interviewer and signed the form once they fully understood all aspects of the study (i.e., all information would be held in strict confidence) and were agreeable to participating. Honourariums were provided to cover expenses (e.g., taxis, buses, gas, parking) and time associated with completing a 3-day food record and attending the office interview (about 180 minutes total).

As part of the face-to-face survey interviews conducted at the MDABC office, respondents brought all medications and natural health products (e.g., vitamin, mineral, herbal, botanical, and homeopathic preparations) they were taking. Details of NHP use based on type, composition (e.g., ingredients and amounts recorded from the labels), and frequency (e.g., taken daily, monthly) were taken by a trained interviewer.

\section{Statistical analysis}

Nutrient and NHP intake data were collected using the standardized procedures of the British Columbia Nutrition Survey (BCNS) that included nutrient analysis of 3-day food records using ESHA software and the Canadian Nutrient File. Full information about the BCNS, nutrient analyses methods, and quality control procedures [25] are detailed elsewhere.

Comparisons of NHP use (e.g., prevalence) were made with the BCNS (population norm) and associated factors such as socio-demographic (i.e., sex, age, relationship status, education, income) and clinical (i.e., medication use, depressive versus bipolar disorder, GAF, years since diagnosis, BMI, psychiatric symptom scores) characteristics were analysed using binomial tests of two proportions, Fisher Exact statistics, Student t-tests, Mann-Whitney tests and correlations where appropriate. Variables that were found to be significant based on the bivariate analysis were then analyzed in the logistic (i.e., NHP use as dichotomous dependent variable) and multiple regression (i.e., number of NHPs used as continuous dependent variable) models to examine factors associated with NHP use. No more than four variables were placed into a model at one time and all models were evaluated to ensure they met statistical test assumptions (e.g., normality, homoscedasticity) and goodness of fit (e.g., graphical depictions of the residuals, Hosmer and Lemeshow's goodness-of-fit test). All statistical analyses were conducted using Stata 7.0 software. 
Safety of NHP Use: Nutrient content in NHPs was recorded for each participant, expressed as a daily amount and added to the usual intake obtained from food sources alone. For example, vitamin $C$ from food sources averaged over 3 days was added to vitamin $C$ from supplements expressed as a daily amount based on previous month's use. Nutrient intakes (from food and NHPs combined) were compared to the Tolerable Upper Intake Levels (UL) of the Dietary Reference Intakes (DRIs), where applicable, to estimate prevalence of excess intakes. The ULs represent a daily nutrient amount for almost all healthy individuals where risk of adverse effects increases as intake levels exceed the standard [26]. For those intakes exceeding the ULs, the amounts were then compared to the Lowest Observed Adverse Effect Levels (LOAELs) of the DRIs, when available. The LOAEL is the lowest amount for which an adverse effect has been reported [26].

For NHPs without DRI comparison data, safety of use was examined by conducting detailed electronic searches of all products taken by participants for any reported adverse events. The databases searched included MEDLINE, EMBASE, PsychINFO, the Cochrane Library, CINAHL, NAPRALERT, MedEffect ${ }^{\mathrm{TM}}$ Canada, International Pharmaceutical Abstracts, CISCOM, and HerbMed. Search terms included common and scientific names, as well as synonyms for the NHPs and their primary active constituents. Adverse events included those reported from individual NHPs as well as any potential interactions that may have occurred from concurrent NHP use and with medications that participants were taking. We refer to this as the potential for adverse events previously defined as an unsafe state, not currently an event, but likely to lead to an event if it persists without intervention [27].

\section{Results \\ Sample}

The response rate was about $75 \%$ (97/129), calculated with the assumption that all the unresolved cases were in-scope (eligible). Those who did not want to participate in the study were asked a set of demographic health behaviour questions including their marital status, education level, use of vitamin and mineral supplements, type of bread and milk they consumed, and whether they smoked; no significant group differences were found between study participants and the non-responders based on these variables. The first author verified with the MDABC that the sample reflected the demographics (e.g., gender, age range) of their membership.

Most of the sample was female $(n=69 ; 71 \% ; 95 \% \mathrm{CI}$ $62 \%$ to $80 \%$ ), had government-defined low income levels ( $\mathrm{n}=47$; 49\%; 95\% CI 39\% to 58\%), had educational attainment levels less than a university degree $(n=76 ; 78.4 \%$; $95 \%$ CI $70 \%$ to $87 \%$ ), tended to carry excess weight (BMI >
$25 ; \mathrm{n}=65 ; 67 \%$; $95 \%$ CI $58 \%$ to $76 \%)$, had bipolar I or II disorder (60\%; $95 \%$ CI $50 \%$ to $70 \%)$, and were considered to be high functioning based on mean GAF scores $(62.7 \pm$ 14.7 ) and median YMRS (Median $=3 ; 25^{\text {th }_{0}} \%$ ile $=1 ; 75^{\text {th }} \%$ ile $=5$ ) and Ham-D scores (Median $=9.7,25^{\text {th }} \%$ ile $=3.75$; $75^{\text {th }} \%$ ile $\left.=14.75\right)$.

\section{Prevalence and characteristics of NHP use}

A total of 267 different NHPs were used in this sample. The proportion of the respondents taking at least one NHP was 66\% (95\% CI 56\% to 75\%). Fifty-eight percent of the sample (95\% CI $47 \%$ to $68 \%$ ) were taking NHPs in combination with their psychiatric medications that mainly included typical and atypical antipsychotics, antidepressants, and mood stabilizers; $8 \%$ (95\% CI 4\% to 16\%) were taking these products without prescription medications. Of those who were taking NHPs, the average (mean) number of products used was 3 (range of 1 to 21 ; $95 \%$ CI 4 to 10). More than half of the sample were taking single or combination vitamin and mineral therapies, herbs and natural products and other nutrients such as glucosamine, amino acids, essential fatty acids from oils, and lactic acid bacteria (Table 1). Males had higher intakes of most single and combination preparations of vitamins, replacement preparations, and other nutrients (Table 1) (range of p's $<0.05$ to 0.0001 ). Comparisons of NHP use based on bivariate and regression statistical analyses with sociodemographic (i.e., age, education, income, relationship status) and clinical factors (i.e., psychiatric medication use, depressive vs. bipolar I and II disorder, GAF, years since diagnosis of mental health condition, BMI, depression scores, mania scores) showed no significant associations.

\section{NHPs and potential for adverse events}

When vitamin and mineral intakes from food and supplements were combined and compared to the DRIs, $2 \%$ ( $95 \%$ CI 0.3 to 7$)$ to $8 \%$ ( $95 \%$ CI 4 to 16 ) of the sample had intakes that exceeded the ULs for 8 nutrients (Table 2); of these, 19\% (95\% CI 11 to 28 ) had niacin intakes above the LOAEL of $50 \mathrm{mg}$, and 6\% (95\% CI 2 to 13) had magnesium intakes above the LOAEL of $360 \mathrm{mg}$. In addition to the NHPs that had DRI comparison data, 16 other products used by 38\% (95\% CI 28 to $49)$ of the total sample were identified that could potentially lead to adverse effects as described in Table 3. The evidence cited in Table 3 often represents anecdotal reports of incidents that ranged from mild gastrointestinal discomfort to significant clinical events including worsening of mental symptoms.

\section{Discussion}

The results of this analysis indicate that there tends to be a higher prevalence of NHP use among persons with 
Table 1 Proportion taking NHPs in the previous month: comparison by sex and to the British Columbia Nutrition Survey (BCNS) (total sample $=97$ )

\begin{tabular}{|c|c|c|c|c|}
\hline NHP & $\begin{array}{c}\text { Males }(n=28) \\
\%(95 \% \mathrm{Cl})\end{array}$ & $\begin{array}{c}\text { Females }(n=69) \\
\%(95 \% \mathrm{Cl})\end{array}$ & $\begin{array}{c}\text { Total }(n=97) \\
\%(95 \% \mathrm{Cl})\end{array}$ & $\begin{array}{c}\text { BCNS }(n=1823) \\
\%(95 \% \text { Cl })\end{array}$ \\
\hline \multicolumn{5}{|l|}{ Water Soluble Vitamins (Single) } \\
\hline Vitamin $B_{6}$ or pyridoxine & $68(51 \text { to } 85)^{* * *}$ & 14 (6 to 23 ) & 31 (22 to 41$)$ & $0^{a}$ \\
\hline Vitamin $B_{9}$ or folic acid & $71(55 \text { to } 88)^{* * *}$ & 28 (17 to 38$)$ & 40 (30 to 51$)$ & $0^{\mathrm{a}}$ \\
\hline Vitamin C & 64 (47 to 82$)$ & 67 (56 to 78$)$ & $66(56 \text { to } 75)^{+++}$ & 24 (22 to 26$)$ \\
\hline \multicolumn{5}{|l|}{ Fat Soluble Vitamins (Single) } \\
\hline Vitamin A & $25(9 \text { to } 41)^{*}$ & $4(0$ to 9$)$ & $10(5 \text { to } 18)^{+++}$ & 2 (1 to 3$)$ \\
\hline Vitamin D & $61(43$ to 79$)$ & 51 (40 to 62 ) & $64(54 \text { to } 79)^{+++}$ & $1(0$ to 2$)$ \\
\hline Vitamin E & 46 (28 to 65$)$ & 46 (35 to 58$)$ & $47(37 \text { to } 58)^{+++}$ & 17 (15 to 19$)$ \\
\hline \multicolumn{5}{|l|}{ Vitamin Combinations } \\
\hline Vitamin B complex (with or without vitamin C) & 68 (51 to 85$)$ & 49 (37 to 61$)$ & $55(44 \text { to } 65)^{+++}$ & 9 (8 to 10$)$ \\
\hline Vitamin $\mathrm{A}$ and $\mathrm{D}$ combination & $21(6 \text { to } 37)^{*}$ & $4(0$ to 11$)$ & $9(4 \text { to } 17)^{++}$ & $3(2$ to 4$)$ \\
\hline Multivitamins & 14 (1 to 27$)$ & 19 (10 to 28$)$ & $18(11 \text { to } 27)^{+}$ & $9(8$ to 10$)$ \\
\hline \multicolumn{5}{|l|}{ Minerals (Single and Combinations) } \\
\hline Iron preparations & 21 (6 to 37$)$ & 20 (11 to 30$)$ & $34(25 \text { to } 44)^{+++}$ & $1(0$ to 2$)$ \\
\hline Single $^{\mathrm{b}}$ and multiple minerals ${ }^{\mathrm{c}}$ & 79 (63 to 94$)$ & 78 (69 to 87$)$ & $78(69 \text { to } 86)^{+++}$ & $13(11$ to 15$)$ \\
\hline \multicolumn{5}{|l|}{ Vitamin and Mineral Combinations } \\
\hline Vitamins and minerals & 61 (43 to 79$)$ & 59 (49 to 71$)$ & $60(49 \text { to } 70)^{+++}$ & 31 (29 to 33$)$ \\
\hline \multicolumn{5}{|l|}{ Other NHPs } \\
\hline Enzymes or gastrointestinal products ${ }^{e}$ & 46 (28 to 65$)$ & 30 (20 to 41$)$ & $35(26 \text { to } 45)^{+++}$ & $6(5 \text { to } 7)^{d}$ \\
\hline Replacement $^{f}$ or homeopathic preparations ${ }^{g}$ & 46 (28 to 65$)$ & 29 (18 to 37$)$ & $34(25 \text { to } 44)^{+++}$ & $5(4$ to 6$)$ \\
\hline Herbal and natural products ${ }^{h}$ & 61 (43 to 79) & 51 (39 to 63) & $54(43 \text { to } 64)^{+++}$ & 19 (17 to 21$)$ \\
\hline Other products ${ }^{i}$ & $61(43 \text { to } 79)^{*}$ & 88 (81 to 96$)$ & $75(65 \text { to } 83)^{+++}$ & 20 (18 to 22$)$ \\
\hline
\end{tabular}

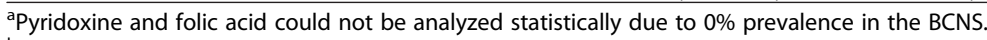

bIncludes chromium, selenium, zinc, and magnesium.

Includes calcium plus magnesium; calcium, magnesium plus zinc; mineral combinations including bromide, calcium, silicon, nitrogen, selenium, phosphorous, iodide, chromium, manganese, titanium, rubidium, cobalt, copper, antimony, molybdenum, strontium, zinc, nickel, tungsten, germanium, scandium, vanadium, tellurium, tin, lanthanum, yttrium, silver, gallium, bismuth, zirconium, cerium, cesium, gold, beryllium, hafnium, samarium, terbium, europium, gadolinium, dysprosium, thorium, holmium, lutetium, erbium, ytterbium, neodymium, praseodymium, niobium, tantalum, thallium, rhenium, indium, and palladium. ${ }^{\mathrm{d}} \mathrm{BCNS}$ proportion $<1 \%$ but rounded to $1 \%$.

eIncludes antacids, adsorbents, laxatives, digestants.

${ }^{f}$ Electrolyte-type supplements intended to prevent or treat electrolyte imbalances that include sports drinks, over-the-counter powders and tablets, overthe-counter electrolyte replenishers, oral rehydration formulae, and multiple electrolyte injections. Most preparations contained sodium, potassium magnesium, and calcium.

${ }^{9}$ Homeopathic preparations contain medicinal ingredients and are prepared in accordance with the methods outlined in homeopathic pharmacopoeias.

${ }^{h}$ Includes herbs, herbal materials, herbal preparations and finished herbal products, that contain as active ingredients parts of plants, or other plant materials, or combinations.

'Includes glucosamine, amino acids, evening primrose oil, coenzyme Q10, flax seed oil, lactic acid bacteria.

Significant differences between males and females at ${ }^{*} p<0.05,{ }^{* *} p<0.001$, and ${ }^{* * *} p<0.0001$.

Significant differences between study sample and BCNS at ${ }^{+} p<0.05,{ }^{++} p<0.001$, and ${ }^{++} p<0.0001$.

mood disorders, particularly males, than in the general population (i.e., BCNS data). A small proportion of the sample exceeded levels deemed to be the upper margin of safety for the general healthy population for 8 nutrients, none of which represented significant harms. Finally, about $38 \%$ of survey respondents were potentially exposing themselves to adverse reactions associated with their use of NHPs that did not contain vitamins or minerals.

The use of NHPs appears to be of a similar scale to that found in other investigations of mental health populations where reported prevalence ranges from 50 to $80 \%$ [4]. The common use of NHPs may be attributable to many factors that include media interest in the topic, increased availability of various information sources (e.g., the Internet), the perceived efficacy and "naturalness" of the therapies, desire to reduce side effects, and dissatisfaction with conventional therapies leading to experimentation with different products [102-104]. Unlike other studies, our results did not indicate differences in NHP use according to socioeconomic status which is contrary to the inverse supplement hypothesis [105], which suggests that those in need of more nutrients due to factors such as disease risk or limited income are usually not the ones who take supplements. People with mood disorders may not consider income a barrier if they believe that the NHPs will alleviate symptoms. 
Table 2 Potential adverse events of vitamin and mineral supplement use based on comparison of nutrient levels to Dietary Reference Intakes and database searches for reported adverse events for individual vitamins and minerals used

\begin{tabular}{|c|c|c|c|c|c|}
\hline Vitamin/mineral & $\mathrm{UL}^{\mathrm{a}}$ & $\begin{array}{l}\%>\mathrm{UL}^{\mathrm{a}} \\
(95 \% \mathrm{Cl})\end{array}$ & LOAEL $^{\mathrm{b}}$ & $\begin{array}{l}\%>\text { LOAEL }^{\mathrm{b}} \\
(95 \% \mathrm{Cl})\end{array}$ & Effect at the LOAEL ${ }^{b}$ \\
\hline \multicolumn{6}{|c|}{ Vitamins and Minerals with ULs ${ }^{\mathrm{a}}$ and LOAELs ${ }^{\mathrm{b}}$} \\
\hline Vitamin $B_{3}$ or niacin - mg & $35^{\mathrm{c}}$ & 28 (19 to 38$)$ & 50 & 19 (11 to 28$)$ & Vasodilation causing flushing of the skin \\
\hline Vitamin $B_{6}$ or pyridoxine - $m g$ & 100 & $8(4$ to 16$)$ & - & - & - \\
\hline Vitamin $\mathrm{B}_{9}$ or folate - mcg & $1000^{c}$ & $17(10$ to 25$)$ & 5000 & $0 \%$ & Precipitate or exacerbate neuropathy in vitamin $B_{12}$ deficient individuals \\
\hline Vitamin $D^{d}-m c g$ and Vitamin $E^{d}-m g$ & $\begin{array}{l}\text { D: } 100 ; \mathrm{E}: \\
1000^{\mathrm{e}}\end{array}$ & $3(1$ to 9$)$ & $\begin{array}{c}\text { D: } 50 ; \text { E: } 39,545 \text { and } \\
18,000^{f}\end{array}$ & $0 \%$ & $\begin{array}{l}\text { Vitamin D: Hypercalcemia. Vitamin E: Increased tendency to hemorrhage } \\
\text { seen in rats }\end{array}$ \\
\hline Calcium - mg & 2500 & $6(2$ to 13$)$ & 5000 & $0 \%$ & Hypercalcemia, renal insufficiency \\
\hline Iron - mg & 45 & 7 (3 to 14$)$ & - & - & - \\
\hline$\overline{\text { Magnesium - mg }}$ & $350^{c ; g}$ & 6 (2 to 13$)$ & 360 & 6 (2 to 13$)$ & Diarrhea \\
\hline Zinc - mg & $40 \mathrm{mg}$ & $6(2$ to 13$)$ & - & - & - \\
\hline Manganese $^{d}-m g$ & $11 \mathrm{mg}$ & 8 (4 to 16$)$ & - & - & - \\
\hline
\end{tabular}

Vitamins and Minerals (without ULs ${ }^{\mathrm{a}}$ and LOAELs ${ }^{\mathrm{b}}$ )

\section{Product names $\quad \%(95 \% \mathrm{Cl}) \quad$ Adverse Events Reported in the Literature $^{\mathrm{h}}$}

Pantothenic acid, vitamin $B_{5}$, pantethine, pantothenol, or

D-pantothenate and Potassium

Forms of pantothenic acid: Diarrhea seen with 10 to 20 grams/day of calcium D-pantothenate [28]. Case report of eosinophilic pleuropericardial effusion in an elderly woman taking $10 \mathrm{mg}$ of biotin and $300 \mathrm{mg}$ of pantothenic acid daily for two months [29].

37 (28 to 49) Nausea and heartburn, have been reported with pantethine [30]

Potassium: Supplementation of potassium only is generally prescribed to treat hypokalemia while preventing hyperkalemia and medication interactions. Mild effects include nausea, vomiting, abdominal discomfort, and diarrhea [28]

aTolerable Upper Intake Level.

bLowest Observed Adverse Effect Level: The lowest intake (or experimental oral dose) at which an adverse effect has been identified.

'The UL for niacin, folate, and magnesium apply to synthetic forms obtained from supplements, fortified foods, or a combination of the two.

${ }^{\mathrm{d} N u t r i e n t}$ analysis software for food intakes of vitamin $\mathrm{E}$, vitamin $\mathrm{D}$ and manganese have less than $50 \%$ coverage for nutrient; thus prevalence estimates of nutrient intakes exceeding the UL are conservative.

'The UL for vitamin $E$ applies to any form of supplemental a-tocopherol, fortified foods, or a combination of the two.

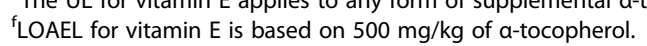

'The UL for magnesium is based on gastrointestinal effects from consumption of $350 \mathrm{mg}$ or more of the synthetic form.

9The UL for magnesium is based on gastrointestinal effects from consumption of $350 \mathrm{mg}$ or more of the synthetic form.
${ }^{\mathrm{h}}$ Based on database searches of MEDLINE, EMBASE, PsychINFO, the Cochrane Library, CINAHL, NAPRALERT, MedEffect ${ }^{\mathrm{m}}$ Canada, International Pharmaceutical Abstracts, CISCOM, and HerbMed.

'Potassium in multi-vitamin and mineral supplements are limited to $99 \mathrm{mg}$ per day. Reported frequency here includes only supplementation of potassium as the single nutrient as adverse effects have only been reported with this. 
Table 3 Descriptions of potential adverse events for non-nutrient based NHPs used by sample based on database search of reported adverse events for each NHP

\section{NHP used in sample}

Cranberry (Vaccinium macrocarpon)

Dehydroepiandrosterone (DHEA) or 5-Dehydro-epiandrosterone

(5-DHEA)

Devil's Claw (Harpago-phytum procumbens)

Dong Quai (Angelica sinensis), Chinese angelica

Echinacea (Echinacea angustifolia, Echinacea pallida, Echinacea purpurea)

Evening Primrose Oil (Oenothera biennis)

Feverfew (Tanacetum parthenium; syn. Chrysanthemum parthenium (L.) Pers., Pyrethrum parthenium Sm.)

Flaxseed (common flax, linseed, Linum usitatissimum)

Garlic (Allium sativum)

Ginkgo (Ginkgo biloba)

Ginseng (American, Asian, Chinese, Korean red; Panax ginseng, Panax spp. including $P$. ginseng and $P$. quinquefolius)

Ginseng (American, Asian, Chinese, Korean red; Panax ginseng, Panax spp. including P. ginseng and $P$. quinquefolius)

Melatonin (N-acetyl-5-methoxytryptamine) Omega-3 Fatty Acids, Alpha-Linolenic Acid
Adverse events reported for that NHP in the literature

More than one litre daily may cause kidney stones [31]. (Note: In this sample, cranberry pills were used and did not exceed this level)

People with mood disorders may experience mania, irritability, and sexual inappropriateness [32-35]

Mild gastrointestinal upset, hypotension, diarrhea, loss of taste, anorexia, headache, and tinnitus [32-34]. May interact with warfarin; one case report of purpura [36]

In a cross-sectional survey $(n=1818)$, one case was identified as a potential significant interaction between dong quai and anticoagulant/antiplatelet agents [37]

Gastrointestinal upset and rashes; in rare cases, has been associated with allergic reactions that may be severe [38]. May interact with amoxicillin [39]

Case reports of seizures in patients with/without known seizure disorders [40,41]. In cross-sectional survey $(n=1818)$, two cases of potential significant interactions with anticoagulant/antiplatelet agents identified [37]

Gastrointestinal upset [42,43], nervousness, insomnia [44], and possible allergic responses in those sensitive to chrysanthemums, daisies, or marigolds. Potential cross-reactivity with other members of the Compositae family [45]. In cross-sectional survey $(n=1818)$, two cases of potential clinically significant interactions with anticoagulant/antiplatelet agents identified [37].

Rarely, flaxseed (not oil form) has caused gastrointestinal distress [46-50]. A double-blind placebo-controlled trial suggested there may be increased episodes of mania and hypomania in people with bipolar disorder [46]

Breath and body odour, and allergic reactions [51]. Excess use associated with spontaneous epidural hematoma [52]. Potential reactions include bleeding and hypoglycemia (likely not clinically significant) [53]. In cross-sectional survey $(n=1818), 25$ cases of potential clinically significant interactions with anticoagulant/antiplatelet agents identified [37]

Surveillance studies (> 10,000 people), found 1.69\% incidence of symptoms such as headache and gastrointestinal complaints [54]. Bleeding indicated in a few case reports [55]. May cause allergic hypersensitivity, including Stevens-Johnson syndrome [56-58]. In crosssectional survey of 1818 patients, 20 cases of potential clinically significant interactions with anticoagulant/antiplatelet agents identified [37]. Infrequent mild gastrointestinal discomfort has been reported when Ginkgo is taken with selective serotonin reuptake inhibitors (SSRIs) [59]. May interact with thiazides [60,61], and nifedipine [62,63]

Long-term use of Panax and American ginseng associated with skin rash, itching, diarrhea, sore throat, loss of appetite, excitability, anxiety, depression, or insomnia [53,64]. Few reports of headache, fever, dizziness/vertigo, blood pressure changes, chest pain, difficult menstruation, heart palpitations, leg swelling, nausea, vomiting, manic episodes in bipolar disorder, or Stevens-Johnson syndrome (may have been due to product contaminants) [53]. High intake of American ginseng may result in hypoglycemia in people with/without diabetes [65]. May interact with anticoagulants/antiplatelets [66,67], diabetes medications [37], digoxin [68], estrogenic agents [69-71], furosemide [72], monoaminergic agents [73-75], nifedipine [76]

Long-term use of Panax and American ginseng associated with skin rash, itching, diarrhea, sore throat, loss of appetite, excitability, anxiety, depression, or insomnia [53,64]. Few reports of headache, fever, dizziness/vertigo, blood pressure changes, chest pain, difficult menstruation, heart palpitations, leg swelling, nausea, vomiting, manic episodes in bipolar disorder, or Stevens-Johnson syndrome (may have been due to product contaminants) [53]. High intake of American ginseng may result in hypoglycemia in people with/without diabetes [65]. May interact with anticoagulants/antiplatelets [66,67], diabetes medications [37], digoxin [68], estrogenic agents [69-71], furosemide [72], monoaminergic agents [73-75], nifedipine [76]

May worsen depression and irritability. Sedative medications (CNS depressants) and benzodiazepines interact with melatonin [77] Caution indicated for those with diabetes as may increase blood glucose, at risk of bleeding, or with high LDL levels [78-85]. May interact with anticoagulants/antiplatelets [80,86-90] 
Table 3 Descriptions of potential adverse events for non-nutrient based NHPs used by sample based on database search of reported adverse events for each NHP (Continued)

Valerian (Valeriana officinalis)

Mild impairments in concentration, processing, fatigue (less pronounced than with benzodiazepines) [91-95], dizziness, and headache [96,97]. Drug "hangover" and "withdrawal" effect has been reported with high doses [96]. Delirium, ameliorated by benzodiazepines, indicated in one case report [98]. Some develop a "paradoxical reaction" leading to nervousness, and use for longer than 2 months may result in insomnia [53]. Rare reports of hepatotoxicity with some preparations that include valerian [99] but may have been due to other components. May interact with CNS depressants [91,92,100]. In cross-sectional survey $(n=1818), 15$ cases of potential clinically

significant interactions with sedatives identified [37]. One case of SSRI use and valerian (with alcohol) indicated mental status changes

${ }^{\mathrm{a}}$ Based on database searches of MEDLINE, EMBASE, PsychINFO, the Cochrane Library, CINAHL, NAPRALERT, MedEffect ${ }^{\text {TM }}$ Canada, International Pharmaceutical Abstracts, CISCOM, and HerbMed for each NHP used in the sample including common and scientific names, synonyms and the primary active constituents of the NHP. 
The potential health risk associated with intakes above the LOAELs (i.e., skin flushing, mild diarrhea) in a few of the participants is relatively minor. Niacin intake excesses may be due to people receiving pharmacological doses (i.e., 1 to 3 grams daily) to manage serum cholesterol levels as per Canadian lipid guidelines [55]; at least 31 participants had high blood cholesterol levels. We previously reported in this same sample that there was a pattern of correlations between some nutrient intakes (even above the ULs) and overall mental health based on GAF scores [106], suggesting that these individuals may have been benefiting from the additional nutrients. We also note that the DRIs are based on healthy populations and may have limited applicability to persons with mental health conditions. For example, lithium in pharmacological doses would certainly be contraindicated in healthy populations, but in individuals with bipolar disorder higher amounts of this mineral are standard treatment. While there was potential for more severe adverse reactions from non-nutrient based NHPs, some of these products are also used as sources for conventional drugs [52].

The modest sample size may be interpreted as a limitation. However, unlike the large population surveys on NHP use, our study collected detailed data (e.g., types, dose, frequency, nutrients from food plus supplements), verified mental health diagnosis, and conducted an assessment of potential for adverse events. The sample was comprised of mainly females, individuals with a mental health condition that were generally high functioning, and resided in an urban region which may limit the generalizability of findings. In addition, it cannot be determined how well MDABC membership reflects the population of all individuals with mood disorders. The prevalence of NHP use in this study may be overstated as the region in which the data was collected is reported to have a higher proportion of alternative medicine practices compared to other Canadian provinces [10]. The prevalence estimate for potential adverse effects may be conservative as data is lacking about interactions of NHPs with each other and with foods, and many surveillance systems are passive and contain incomplete data (e.g., a specific dose level that led to an adverse effect). Conversely, the potential for adverse events may be overstated as the information obtained tended to be based on anecdotal reports and not prospective data that specifically documents harms.

\section{Conclusions}

Since NHP use among individuals with mood disorders is prevalent, health care providers may best serve these clients by becoming more knowledgeable about their characteristics. Further research on the safety of NHPs including their impact on the course and prognosis of mental health conditions is also of relevance.

\begin{abstract}
Abbreviations
BCNS: British Columbia Nutrition Survey; Cl: Confidence Interval;

LOAEL: Lowest Observed Adverse Effect Level; NHP: Natural Health Product; mcg: Micrograms; mg: Milligrams; UL: Tolerable Upper Intake Level.
\end{abstract}

\section{Competing interests}

The authors declare that they have no competing interests.

\section{Authors' contributions}

KMD and BJK designed the study and planned its coordination and data collection. KMD carried out the data collection as part of her PhD dissertation, under the supervision of BJK. Both authors worked on writing the manuscript. Both authors read and approved the final manuscript.

\section{Authors' information}

KMD carried out this study as part of her requirement for a $\mathrm{PhD}$ in the Faculty of Medicine, University of Calgary, under the supervision of BJK, and is currently a postdoctoral research fellow (Chronic Condition Self-Management) in the School of Population and Public Health at the University of British Columbia. BJK is a Professor in the Faculty of Medicine at the University of Calgary who studies nutrition in relation to mental development and function.

\section{Acknowledgements}

The authors thank their funding source, The Danone Research Institute. The second author also thanks the Alberta Children's Hospital Research Institute for ongoing support. We also acknowledge the assistance of the Mood Disorders Association of British Columbia for providing support staff, office space and assistance with recruitment.

\section{Funding and support}

Financial Support for this project was obtained from The Danone Research Institute, which played no role in carrying out the study, analyzing the results, or influencing publication.

\section{Author details}

${ }^{1}$ Department of Community Health Sciences, University of Calgary, Calgary, AB, Canada. ${ }^{2}$ University of British Columbia, School of Population and Public Health, 2206 East Mall, Vancouver BC V6T 1Z3, Canada. ${ }^{3}$ Department of Paediatrics, University of Calgary, Calgary, AB, Canada.

Received: 17 October 2012 Accepted: 27 March 2013

Published: 9 April 2013

\section{References}

1. Health Canada: Natural Health Products. Ottawa: Health Canada; 2012. Retrieved: www.hc-sc.gc.ca/dhp-mps/prodnatur/index-eng.php.

2. Eisenberg DM, Davis RB, Ettner SL, Appel S, Wilkey S, Van Rompay M, Kessler RC: Trends in alternative medicine use in the United States, 1990-1997: results from a follow up national survey. JAMA 1998, 280:1569-1575.

3. Thomas KJ, Nicholl JP, Coleman P: Use and expenditure on complementary medicine in England: a population based survey. Complement Ther Med 2001, 9:2-11.

4. Ernst E: Prevalence of use of complementary/alternative medicine: a systematic review. Bull World Health Organ 2000, 78:252-257.

5. Simpson JE: Utilization patterns and trends. Health Policy Research Bulletin 2003, 7:9-13.

6. Wahlström M, Sihvo S, Haukkala A, Kiviruusu O, Pirkola S, Isometsä E: Use of mental health services and complementary and alternative medicine in persons with common mental disorders. Acta Psychiatr Scand 2008, 118:73-80.

7. Barnes PM, Powell-Griner E, McFann K, Nahin RL: Complementary and alternative medicine use among adults: United States, 2002. Advance data from vital and health statistics. Hyattsville, Maryland: National Center for Health Statistics; 2004.

8. Unützer J, Klap R, Sturm R, Young AS, Marmon T, Shatkin J, Wells KB: Mental disorders and the use of alternative medicine: results from a national survey. Am J Psychiatry 2000, 157:1851-1857.

9. Kessler RC, Soukup J, Davis RB, Foster DF, Wilkey SA, Van Rompay MI, Eisenberg DM: The use of complementary and alternative therapies to 
treat anxiety and depression in the United States. Am J Psychiatry 2001, 158:289-294.

10. Wang J, Patten S, Russell M: Alternative medicine use by individuals with major depression. Can J Psychiatry 2001, 46:528-533.

11. Assion HJ, Zarouchas I, Multamäki S, Zolotova J, Schröder SG: Patients' use of alternative methods parallel to psychiatric therapy: does the migrational background matter. Acta Psychiatr Scand 2007, 116:220-225.

12. Martin TG: Serotonin syndrome. Ann Emerg Med 1996, 28:520-526.

13. World Alliance for Patient Safety: WHO Draft Guidelines for Adverse Event Reporting and Learning Systems from Information to Action. Geneva: WHO; 2005.

14. Bell I, Edman J, Morrow F, Marby DW, Perrone G, Kayne HL, Greenwald M, Cole JO: Vitamin $B_{1}, B_{2}$, and $B_{6}$ augmentation of tricyclic antidepressant treatment in geriatric depression with cognitive dysfunction. J Am Coll Nutr 1992, 11:159-163.

15. Sarris J, Kavanagh DJ, Byrne G: Adjuvant use of nutritional herbal medicines with antidepressants, mood stabilizers and benzodiazepines. J Psychiatr Res 2010, 44:32-41.

16. Kaplan BJ, Simpson JSA, Ferre RC, Gorman CP, McMullen DM, Crawford SG: Effective mood stabilization in bipolar disorders with a chelated minera supplement. J Clin Psychiatry 2001, 62:936-944.

17. Sarris J, Mischoulon D, Schweitzer I: Adjunctive nutraceuticals with standard pharmacotherapies in bipolar disorder: a systematic review of clinical trials. Bipolar Disord 2011, 13:454-465.

18. Rosner B: Fundamentals of Biostatistics. Pacific Grove: Duxbury; 2004.

19. Barr SI: British Columbia Nutrition Survey: Report on Supplements. Victoria, BC: BC Ministry of Health Services; 2004.

20. First MB, Spitzer RL, Gibbon M, Williams JBW: Structured Clinical Interview for DSM-IV-TR Axis I Disorders, Research Version, Non-patient Edition. (SCID-I/NP). New York: Biometrics Research, New York State Psychiatric Institute; 2001.

21. Jones SH, Thornicroft G, Coffey M, Dunn G: A brief mental health outcome scale-reliability and validity of the global assessment of functioning (GAF). Br J Psychiatry 1995, 166(5):654-659.

22. Hamilton M: A rating scale for depression. J Neurol Neurosurg Psychiatry 1960, 23:62

23. Young RC, Biggs JT, Ziegler VE, Meyer DA: A rating scale for mania: reliability, validity and sensitivity. Br J Psychiatry 1978, 133:429-435.

24. Davison KM, Kaplan BJ: Vitamin and mineral intakes in adults with mood disorders: comparisons to nutrition standards and associations with sociodemographic and clinical variables. J Am Coll Nutr 2011, 30(6):547-558.

25. BC Ministry of Health Services: British Columbia Nutrition Survey - Report on Energy and Nutrient Intakes. Victoria: British Columbia: Ministry of Health Services; 2004.

26. Institute of Medicine: Dietary Reference Intakes: Applications in Dietary Assessment. Washington: National Academies Press; 2000.

27. Sarkar U, Handley MA, Gupta R, Tang A, Murphy E, Seligman HK, Shojania KG, Schillinger D: What happens between visits? Adverse and potential adverse events among a low-income, urban, ambulatory population with diabetes. Qual Saf Health Care 2010, 19(3):223-228.

28. Hendler SS: Rorvik DR, eds: PDR for Nutritional Supplements. Montvale: Medical Economics Company, Inc.; 2001

29. Flodin N: Pharmacology of micronutrients. New York: Alan R. Liss, Inc.; 1988

30. Debourdeau PM, Djezzar S, Estival JL, Zammit CM, Richard RC, Castot AC: Life-threatening eosinophilic pleuropericardial effusion related to vitamins $\mathrm{B}_{5}$ and $\mathrm{H}$. Ann Pharmacother 2001, 35(4):424-426.

31. Natural Standard Research Collaboration: Natural Standard: The Authority on Integrative Medicine. www.naturalstandard.com

32. Markowitz JS, Carson WH, Jackson CW: Possible dihydroepiandrosteroneinduced mania. Biol Psychiatry 1999, 45:241-242.

33. Johnson MD, Bebb RA, Sirrs SM: Uses of DHEA in aging and other disease states. Ageing Res Rev 2002, 1:29-41.

34. Grahame R, Robinson BV: Devil's claw (Harpagohytum procumbens): pharmacological and clinical studies. Ann Rheum Dis 1981, 40(6):632.

35. Shaw D, Leon C, Kolev S, Murray V: Traditional remedies and food supplements. A 5-year toxicological study (1991-1995). Drug Saf 1997, 17(5):342-356.

36. Belaiche $P$ : Etude clinique de 630 cas d'artrose traits par le nebulisat aqueux d'Harpagophytum procumbens (Radix). Phytotherapy 1982, 1:22-28.

37. Sood A, Sood R, Brinker FJ, Mann R, Loehrer LL, Wahner-Roedler DL: Potential for interactions between dietary supplements and prescription medications. Am J Med 2008, 121(3):207-211.

38. Huntley AL, Thompson Coon J, Ernst E: The safety of herbal medicinal products derived from Echinacea species: a systematic review. Drug Saf 2005, 28(5):387-400.
39. Anonymous: Immunallergische reaktionen nach Echinacea-estrakten (Echinacin, Exberitox N U.A.). Arnzei-telegramm 1991, 39.

40. Janes SE, Price CS, Thomas D: Essential oil poisoning: N-acetylcysteine for eugenol-induced hepatic failure and analysis of a national database. Eur J Pediatr 2005, 164(8):520-522

41. Vaddadi KS: The use of gamma-linolenic acid and linoleic acid to differentiate between temporal lobe epilepsy and schizophrenia. Prostaglandins Med 1982, 6(4):375-379.

42. Murphy JJ, Heptinstall S, Mitchell JR: Randomised double-blind placebocontrolled trial of feverfew in migraine prevention. Lancet 1988, 2(8604):189-192.

43. Awang DVC: Parthenocide: the demise of facile theory of feverfew activity. J Herbs Spices Med Plants 1998, 5(4):95-98.

44. Johnson ES, Kadam NP, Hylands DM, Hylands PJ: Efficacy of feverfew as prophylactic treatment of migraine. BMJ 1985, 291:569-573.

45. Sriramarao P, Rao PV: Allergenic cross-reactivity between Parthenium and ragweed pollen allergens. Int Arch Allergy Immunol 1993, 100(1):79-85.

46. Stoll AL, Severus WE, Freeman MP, Rueter S, Zboyan HA, Diamond E, Cress KK, Marangell LB: Omega 3 fatty acids in bipolar disorder: a preliminary doubleblind, placebo-controlled trial. Arch Gen Psychiatry 1999, 56:407-412.

47. Tarpila S, Kivinen A: Ground flaxseed is an effective hypolipidemic bulk laxative [published abstract]. Gastroenterology 1997, 112:A836.

48. Cunnane SC, Hamadeh MJ, Liede AC, Thompson LU, Wolever TM, Jenkins DJ: Nutritional attributes of traditional flaxseed in healthy young adults. Am J Clin Nutr 1995, 61(1):62-68.

49. Alonso L, Marcos ML, Blanco JG, Navarro JA, Juste S, del Mar GM, Perez R, Carretero PJ: Anaphylaxis caused by linseed (flaxseed) intake. J Allergy Clin Immunol 1996, 98(2):469-470.

50. Lezaun A, Fraj J, Colas C, Duce F, Dominguez MA, Cuevas M, Eiras P: Anaphylaxis from linseed. Allergy 1998, 53(1):105-106.

51. Morbidoni L, Arterburn J, Young V, Mullins D, Mulrow C, Lawrence V: Garlic: Its history and adverse effects. J Herb Pharmacother 2001, 1(1):63-83.

52. Rose KD, Croissant PD, Parliament CF, Levin MB: Spontaneous spinal epidural hematoma with associated platelet dysfunction from excessive garlic ingestion: a case report. Neurosurgery 1990, 26(5):880-882.

53. Ulbricht C, Chao W, Costa D, Rusie-Seamon E, Weissner W, Woods J: Clinical evidence of herb-drug interactions: a systematic review by the natural standard research collaboration. Curr Drug Metab 2008, 9:1063-1120.

54. Burkard G: The efficacy and safety of ginkgo biloba extract in dementia. Fortschr Med [Supp] 1991, 109(107):6-8.

55. Genest J, McPherson R, Frohlich J, Anderson T, Campbell N, Carpentier A, Couture P, Dufour R, Fodor G, Francis GA, Grover S, Gupta M, Hegele RA, Lau DC, Leiter L, Lewis GF, Lonn E, Mancini GB, Ng D, Pearson GJ, Sniderman A, Stone JA, Ur E: Canadian Cardiovascular Society/Canadian guidelines for the diagnosis and treatment of dyslipidemia and prevention of cardiovascular disease in the adult - 2009 recommendations. Can J Cardio/ 2009, 25(10):567-579.

56. Tomb RR, Fossereau J, Sell Y: Mini-epidemic of contact dermatitis from ginkgo tree fruit (Ginkgo biloba L.). Contact Dermatitis 1988, 19(4):281-283.

57. Becker LE, Skipworth GB: Ginkgo- tree dermatitis, stomatitis, and proctitis. JAMA 1975, 231(11):1162-1163.

58. Davydov L, Stirling AL: Stevens-Johnson syndrome with Ginkgo biloba. J Herb Pharmacother 2001, 1(3):65-69.

59. Cohen AJ, Bartlik B: Ginkgo biloba for antidepressant-induced sexual dysfunction. J Sex Mar Ther 1998, 24:139-143.

60. Kudolo GB: The effect of 3-month ingestion of Ginkgo biloba extract on pancreatic beta-cell function in response to glucose loading in normal glucose tolerant individuals. J Clin Pharmacol 2000, 40(6):647-654.

61. Winther KA, Randløv C, Rein E, Mehlsen J: Effects of Ginkgo biloba extract on cognitive function and blood pressure in elderly subjects. CTR 1998, 59(12):881-888.

62. Yoshioka M, Ohnishi N, Sone N, Egami S, Takara K, Yokoyama T, Kuroda K: Studies on interactions between functional foods or dietary supplements and medicine III. Effects of ginkgo biloba leaf extract on the pharmacokinetics of nidedipine in rats. Biol Pharm Bull 2004, 27(12):2042-2045.

63. Yoshioka M, Ohnishi N, Koishi T, Obata Y, Nakagawa M, Matsumoto T, Tagagi K, Takara K, Ohkuni T, Yokoyama T, Kuroda K: Studies on interactions between functional food or dietary supplements and medicine IV. Effects of ginkgo biloba leaf extract on the pharmacokinetics and pharmacodynamics of nifedipine in healthy volunteers. Biol Pharm Bull 2004, 27(12):2006-2009. 
64. Coon JT, Ernst E: Panax ginseng: a systematic review of adverse effects and drug interactions. Drug Saf 2002, 25(5):323-344.

65. Vuksan V, Sievenpiper JL, Koo VY, Francis T, Beljan-Zdravkovic U, Xu Z, Vidgen E: American ginseng Panax quinquefolius $\mathrm{L}$ ) reduces postprandial glycemia in nondiabetic subjects and subjects with type 2 diabetes mellitus. Arch Int Med 2000, 160(7):1009-1013.

66. Janetzky K, Morreale AP: Probable interaction between warfarin and ginseng. Am J Health Syst Pharm 1997, 54(6):692-693.

67. Cheng TO: Ginseng-warfarin interaction. ACC Curr J Rev 2000, 9(1):84

68. Ding DZ, Shen TK, Cui YZ: Effects of red ginseng on the congestive heart failure and its mechanism. Chin J Integr Med 1995, 15(6):325-327.

69. Lee YJ, Jin YR, Lim WC, Park WK, Cho JY, Hang S, Lee SK: Ginsenoside-Rb1 acts as a weak phytoestrogen in MCF-7 human breast cancer cells. Arch Pharm Res 2003, 26(1):58-63.

70. Bae EA, Shin JE, Kim DH: Metabolism of ginsenoside Re by human intestinal microflora and its estrogenic effect. Biol Pharm Bull 2005, 28(10):1903-1908.

71. Lee $Y$, Jin Y, Lim W, Ji S, Choi S, Jang S, Lee S: A ginsenoside-RH1, a component of ginseng saponin, activates estrogen receptor in human breast carcinoma MCF-7 cells. J Steroid Biochem Mol Biol 2003, 84(4):464-468.

72. Becker BN, Greene J, Evanson J, Chidsey G, Stone WJ: Ginseng-induced diuretic resistance. JAMA 1996, 276(8):606-607.

73. Jones BD, Runikis AM: Interaction of ginseng with phenelzine. J Clin Psychopharmacol 1987, 7(3):201-202.

74. Fugh-Berman A: Herb-drug interactions. Lancet 2000, 355(9198):134-138.

75. Shader Rl, Greenblatt DJ: Phenelzine and the dream machine-ramblings and reflections. J Clin Psychopharmacol 1985, 5(2):65.

76. Smith M, Lin KM, Zheng YP: PIII-89 an open trial of nifedipine-herb interations: nifedipine with St. John's wort, ginseng or ginkgo biloba. Clin Pharmacol Ther 2001, 69:86.

77. Lam RW: Sleep disturbances and depression: a challenge for antidepressants. Int Clin Psychopharmacol 2006, 21:S25-S29.

78. Knapp HR: Dietary fatty acids in human thrombosis and hemostasis. Am J Clin Nutr 1997, 65(5 Suppl):1687S-1698S.

79. Archer SL, Green D, Chamberlain M, Dyer AR, Liu K: Association of dietary fish and $n-3$ fatty acid intake with hemostatic factors in the coronary artery risk development in young adults (CARDIA) study. Arterioscler Thromb Vasc Biol 1998, 18(7):1119-1123.

80. Weksler BB: Omega 3 fatty acids have multiple antithrombotic effects. World Rev Nutr Diet 1994, 76:47-50.

81. Kromann N, Green A: Epidemiological studies in the Upernavik district, Greeland. Incidence of some chronic diseases 1950-1974. Acta Med Scand 1980, 208(5):401-406.

82. Stacpoole PW, Alig J, Ammon L, Crockett SE: Dose-response effects of dietary marine oil on carbohydrate and lipid metabolism in normal subjects and patients with hypertriglyceridemia. Metabolism 1989, 38(10):946-956.

83. Vanschoonbeek K, Feijge MA, Paquay M, Rosing J, Saris W, Kluft C, Giesen $P L$, de Maat MP, Heemskerk JW: Variable hypocoagulant effect of fish oil intake in humans: modulation of fibrinogen level and thrombin generation. Arterioscler Thromb Vasc Biol 2004, 24(9):1734-1740.

84. Friedberg CE, Janssen MJ, Heine RJ, Grobbee DE: Fish oil and glycemic control in diabetes. A meta-analysis. Diabetes Care 1998, 21(4):494-500

85. Montori VM, Farmer A, Wollan PC, Dinneen SF: Fish oil supplementation in type 2 diabetes: a quantitative systematic review. Diabetes Care 2000, 23(9):1407-1415.

86. Goodnight SH Jr, Harris WS, Connor WE: The effects of dietary omega 3 fatty acids on platelet composition and function in man: a prospective, controlled study. Blood 1981, 58(5):880-885.

87. von Houwelingen R, Nordøy A, van der Beek E, Houtsmuller U, de Metz M, Hornstra G: Effect of a moderate fish intake on blood pressure, bleeding time, haematology, and clinical chemistry in healthy males. Am J Clin Nutr 1987, 46(3):424-436

88. Lorenz R, Spengler U, Fischer S, Duhm J, Weber PC: Platelet function, thromboxane formation and blood pressure control during supplementation of the Western diet with cod liver oil. Circulation 1983, 67(3):504-511.

89. Ahmed AA, Holub BJ: Alteration and recovery of bleeding times, platelet aggregation and fatty acid composition of individual phospholipids in platelets of human subjects receiving a supplement of cod-liver oil. Lipids 1984, 19(8):617-624.

90. Buckley MS, Goff AD, Knapp WE: Fish oil interaction with warfarin. Ann Pharmacother 2004, 38(1):50-52.
91. Kuhlmann J, Berger W, Podzuweit $H$, Schmidt $U$ : The influence of valerian treatment on "reaction time, alertness, and concentration" in volunteers. Pharmacopsychiatry 1999, 32:235-241.

92. Gerhard U, Linnenbrink N, Georghiadou C, Hobi V: Vigilanzmindernde Effekte zweier pfazlicher Schlafmittel (Effects of two plant-based sleep remedies on vigilance). Schweiz Rundsch Med Prax 1996, 85:473-481.

93. Kohnen R, Oswald WD: The effects of valerian, propranolol, and their combination on activation, performance, and mood of healthy volunteers under social stress conditions. Pharmacopsychiatry 1988, 21:447-448.

94. Boeters $\mathrm{VU}$ : On treatment of control disorders of the autonomic nervous system with valepotraten (Valmane). Munch Med Wochenschr 1969, 37:1873-1876.

95. Leathwood PD, Chaufard F: Aqueous extract of valerian reduces latency to fall asleep in man. Planta Med 1985, 2:144-148.

96. Kamm-Kohl AV, Jansen W, Brockmann P: Moderne baldrian-therpie gegen nervose Storungen in Senium. Medwelt 1984, 35:1450-1454.

97. Seifert $\mathrm{T}$ : Therapeutic effects of valerian in nervous disorders. Therapeutikon 1988, 2:94-98.

98. Garges HP, Varia I, Doraiswamy PM: Cardiac complications and delerium associated with valerian root withdrawal. JAMA 1998, 280:1566-1567.

99. MacGregor FB, Abernethy VE, Dahabra S, Cobden I, Hayes PC: Hepatotoxicity of herbal remedies. BMJ 1989, 299(6708):1156-1157.

100. Plushner SL: Valerian: Valeriana. Officinalis. Am J Health Syst Pharm 2000, 57(4):328-333. 335

101. Muller D, Pfeil T, von den Driesch V: Treating depression comorbid with anxiety-results of an open, practice-oriented study with St. John's wort WS 5572 and valerian extract in high doses. Phytomedicine 2003, 10(Suppl 4):25-30.

102. Katzman MA, Jacobs L, Marcus M, Vermani M, Logan AC: Weight gain and psychiatric treatment: is there a role for green tea and conjugated linoleic acid? Lipids Health Dis 2007, 6:14.

103. Lipowski ZJ: Somatization: the concept and its clinical applications. Am J Psychiatry 1988, 145:1358-1368.

104. Astin JA: Why patients use alternative medicine: results of a national study. JAMA 1998, 279:1548-1553.

105. Balluz LS, Kieszak SM, Philen RM, Mulinare J: Vitamin and mineral supplement use in the United States. Arch Fam Med 2000, 9:258-262.

106. Davison KM, Kaplan BJ: Nutrient intakes are correlated with overall psychiatric functioning in adults with mood disorders. Can J Psychiatry 2012, 57(2):85-92.

\section{doi:10.1186/1472-6882-13-80}

Cite this article as: Davison and Kaplan: Nutrient- and non-nutrient-based natural health product (NHP) use in adults with mood disorders:

prevalence, characteristics and potential for exposure to adverse events. BMC Complementary and Alternative Medicine 2013 13:80.

\section{Submit your next manuscript to BioMed Central and take full advantage of:}

- Convenient online submission

- Thorough peer review

- No space constraints or color figure charges

- Immediate publication on acceptance

- Inclusion in PubMed, CAS, Scopus and Google Scholar

- Research which is freely available for redistribution 